Pharmaceutical and Biomedical Research

\title{
In-vitro inhibitory effect of ethanolic and methanolic extract of Scrophularia striata on Candida spp.
}

\author{
Mandana Ahmadi ${ }^{1 *}$, Hossein Mahdavi $^{1}$, Mahboobeh Madani ${ }^{2}$, Zohreh Hadadi $^{1}$ \\ ${ }^{1}$ Research and Development Department, Sinafaravar pharmaceutical Company, Najaf abad, Isfahan, Iran \\ ${ }^{2}$ Department of Microbiology, Falavarjan Branch, Islamic Azad University, Isfahan, Iran \\ Received: Aug 24, 2016, Revised: Nov 2, 2016, Accepted: Jan 14, 2017
}

\begin{abstract}
Candida species are the most common cause of opportunistic fungal infection worldwide. Due to increasing resistance of fungi against conventional drugs, as well as their side effects, alternative natural products have become a renewed interest. In the current study, the anti-Candida activities of Scrophularia striata extract were examined. In this experimental study, microdilution assay and well diffusion test were used to determine in vitro anti-fungal effects of ethanolic and methanolic extract of Scrophularia striata on four species of Candida including Candida albicans ATCC 1167, ATCC 1677, tropicalis, and glabrata. The results showed that $100 \mathrm{mg} / \mathrm{ml}$ methanolic extract has more anticandida activity than ethanolic extract. Diameter of inhibiting growth environment for ethanol extract was $37 \mathrm{~mm}$, and MIC and MFC were 2.1 and $41.5 \mathrm{~mm} / \mathrm{ml}$. Results show that ethanolic and methanolic extract of Scrophularia striata have anti-fungal activities. Therefore results of this study suggest this extract is a promising anti-fungal agent, and future experiments will interest for performing in vivo study.
\end{abstract}

Keywords: Scrophularia striata, Candida, ehanolic extract, methanolic extract

Pharm Biomed Res 2016; 2(4): 38-43

\section{Introduction}

In the past two decades, the prevalence of candidiasis has been increased. Candida species are able to create superficial and systemic infections (1). Candida albicans is an opportunistic pathogen, causing mycoses in immunocompromised patients as well as long-term antibiotic users (2-4). Also, other Candida species such as C.glabrata, C.parapsilosis, C.tropicalis and C.krusei are among the oral mucosal lesions suspected agents in AIDS patients (4-6). Medicinal plants may demonstrate a valuable, original source of recent antifungal drugs and have been shown to contain diverse biochemical and pharmacological actions $(7,8)$. Their antifungal activity has been showed against some Candida species (9-11).

One of the plants proposed to have immunomodulatory and anti-inflammatory effects is Scrophularia striata Boiss (Scrophulariaceae). Scrophularia striata (in the Scrophulariacea family) is vernacular to Iran.
Scrophularia striata color is purple (12-14). Many Scrophularia species have been investigated and several compounds from different classes of secondary metabolites including iridoids, phenyl propanoids, phenolic acids, flavonoids, quercetin, isorhamnetin 3Orutinoside and saponins by column chromatography have been isolated (15). These compounds usually are found in root, leaves, or buds of the plant $(16,17)$. Scrophularia striata traditionally has been used for infections, high blood pressure, and stomach disorders (18-20).

previous studies have suggested the inhibitory effect of S.striata extract on microorganisms $(21,22)$. In addition, anti-inflammatory, and immunomodulatory activity of some species of Scrophularia have been showed $(23,24)$. In the present study, we investigated the in vitro inhibitory effects of Scrophularia striata ethanolic and 
metanolic extract on including Candida albicans ATCC 1167, ATCC 1677, tropicalis, and glabrata.

\section{Materials and method}

This is an experimental study conducted on Candida albicans ATCC 1167, ATCC 1677, tropicalis, and glabrata. Scrophularia striata was collected in 2013 May from Zagros mountain in Ilam, Iran and was detected by research center of natural resources in herbarium department in Isfahan.

All part of the plant were washed and dried. Then areal parts of plants such as stalk and leaves were powdered by electric blender. Themaceration method was used to make alcoholic extract. Then, $50 \mathrm{~g}$ was macerated with $100 \mathrm{~mL}$ of $80 \%$ ethanol and methanol on a rotary shaker for 48 and 72 hours, filtered, and then the solution. After, the extracts were taken and filtered by using a millipore filter paper. Then, the extracts were concentrated using a rotary evaporator at $40{ }^{\circ} \mathrm{C}$ under reduced pressure. Finally, the extracts were dried and stored at $4{ }^{\circ} \mathrm{C}$ till their usage in the different tests. The extracts were dissolved in dimethylsulfoxide (DMSO).

Herbal component can be dissolved in methanol, ethanol, percolation or maceration can be used to extract them. The advantage of alcohol extraction is that different alkaloids or alkaline salts can be suit, in addition to the water-soluble impurities such as polysaccharides, proteins are less extracted but its drawback is more fat-soluble impurities is extracted.

Antifungal activity was studied by the agar well diffusion method. Sabouraud dextrose agar (SDA) was used as the fungal medium. The effect of extract antimicrobial were assessed in the concentration include 3.14, 6.25, 12.5, 25, 50 , and $100(\mathrm{mg} / \mathrm{ml})$ using agar well diffusion method and also by determination minimum inhibitory concentration (MIC) and minimum fungicidal concentration (MFC) using microdilution test method. The extracts were diluted in $1 \mathrm{~mL}$ of dimethylsulphoxide (DMSO) at the concentrations of $3.14,6.25,12.5,25,50$, and $100(\mathrm{mg} / \mathrm{ml})$ sabouraud dextrose agar. Petridishes $(8 \mathrm{~cm}$ diameter $)$ containing $20 \mathrm{ml}$ of SDA were used for antifungal activity assay, performed on solid media by the well diffusion method sterile. Wells were prepared in the seeded agar petridishes. The study compound was introduced in the well $(6 \mathrm{~mm})$. The plate were incubated at $37^{\circ} \mathrm{C}$ for $24-48$ h. Growth inhabitation of each fungal strains was counted as the percentage of prevent of radial grow relative to the control, fluconazol. A standard antifungal agent, fluconazol served as a positive control and DMSO was used as a negative control. To identify the minimum inhibitory concentration (MIC) microdilution method was used. In this experiment microplates of 96 cells were used in the first row wells 100 microliter of cultivation medium of SDA were put, then 100 microliter of the extract of the plant was added to the first well. Then 100 microliter of extract was added to the second wells and it was repeated until the stage in which 10 microliter of ferment suspension containing 1000 cells in each milliliter was added to the same well. In each row Alcohol with medium culture and ferment served as negative control and stril physiologic serum with culture medium and ferment served as positive control $(24,25)$.

\section{Statistical analysis}

The experiment was performed three times to minimize the error and the mean values are presented. Data were analyzed using ANOVA test in the $p<0.05$ (SPSS Software, Chicago, USA)

\section{Results}

The growth inhibition value of ethanolic and methanolic extracts of S.striata on Candida albicans ATCC 1167, ATCC 1677, tropicalis, and glabrata in tables 1 and 2 are shown.

The strongest activity was seen against C.glabrata with a range of $41.3 \mathrm{~mm}$ mean inhibition zones and 15.62-21.87 $\mathrm{mg} / \mathrm{ml}$ MIC values. The MIC and MFC of these extracts are currently being obtained in table 3.The methanolic extract of the tested plant has more anti-candida effects as compared to the ethanolic extract. Moreover, the results showed that $100 \mathrm{mg} / \mathrm{ml}$ methanolic extract has more anticandida activity.

\section{Discussion}

Different studies have indicated that the many species of Scrophularia contains substances that have antimicrobial activities (26-29). Results obtained in pervious study show that Scrophularia striata extracts have selective antimicrobial activity on the basis of the cellwall differences of bacterial and fungal microorganisms $(30,31)$. In recent years, tendency of using natural sources as alternative medicine has been raised (32). 
Table 1 The antifungal activity of methanolic extract of $S$. striata on Candida spp*

\begin{tabular}{ccccccc}
\hline $\begin{array}{c}\text { Concentration } \\
\text { Fungi }\end{array}$ & $3.12 \mathrm{mg} / \mathrm{ml}$ & $6.25 \mathrm{mg} / \mathrm{ml}$ & $12.5 \mathrm{mg} / \mathrm{ml}$ & $25 \mathrm{mg} / \mathrm{ml}$ & $50 \mathrm{mg} / \mathrm{ml}$ & $100 \mathrm{mg} / \mathrm{ml}$ \\
\hline $\begin{array}{c}\text { Candida } \\
\text { albicans } \\
\text { (1167) }\end{array}$ & $3.66 \pm 1.52$ & $12.33 \pm 1.50$ & $19.83 \pm 1.25$ & $26.50 \pm 1.80$ & $37 \pm 2$ & $39.5 \pm 0.5$ \\
\hline $\begin{array}{c}\text { Candida } \\
\text { albicans } \\
\text { (1677) }\end{array}$ & $4.66 \pm 2.08$ & $11.83 \pm 1.60$ & $22.16 \pm 1.89$ & $25.16 \pm 1.60$ & $28.8 \pm 0.7$ & $34.6 \pm 4$ \\
\hline $\begin{array}{c}\text { Candida } \\
\text { tropicalis }\end{array}$ & $3.00 \pm 0.30$ & $12.00 \pm 3.40$ & $18.23 \pm 23.00$ & $24.50 \pm 3.91$ & $28.8 \pm 2.0$ & $34.6 \pm 2.4$ \\
\hline $\begin{array}{c}\text { Candida } \\
\text { glabrata }\end{array}$ & $3.00 \pm 2.00$ & $13.86 \pm 0.80$ & $18.50 \pm 0.50$ & $28.00 \pm 1.00$ & $37.3 \pm 2.0$ & $41.3 \pm 3.0$ \\
\hline
\end{tabular}

* Data present as mm $($ Mean $\pm \mathrm{SD})$

Table 2 The antifungal activity of ethanolic extract of S. striata on Candida spp*

\begin{tabular}{|c|c|c|c|c|c|c|}
\hline $\begin{array}{c}\text { Concentration } \\
\text { Fungi }\end{array}$ & $3.12 \mathrm{mg} / \mathrm{ml}$ & $6.25 \mathrm{mg} / \mathrm{ml}$ & $12.5 \mathrm{mg} / \mathrm{ml}$ & $25 \mathrm{mg} / \mathrm{ml}$ & $50 \mathrm{mg} / \mathrm{ml}$ & $100 \mathrm{mg} / \mathrm{ml}$ \\
\hline $\begin{array}{c}\text { Candida } \\
\text { albicans } \\
(1167)\end{array}$ & - & $\begin{array}{c}3.16 \pm 0.28 \\
\mathrm{~mm}\end{array}$ & $\begin{array}{c}7.16 \pm 0.28 \\
\mathrm{~mm}\end{array}$ & $\begin{array}{c}12.00 \pm 0.50 \\
\mathrm{~mm}\end{array}$ & $\begin{array}{c}18.23 \pm 0.76 \\
\mathrm{~mm}\end{array}$ & $\begin{array}{c}25.33 \pm 4.33 \\
\mathrm{~mm}\end{array}$ \\
\hline $\begin{array}{c}\text { Candida } \\
\text { albicans } \\
\text { (1677) }\end{array}$ & - & $\begin{array}{c}4.83 \pm 0.73 \\
\mathrm{~mm}\end{array}$ & $\begin{array}{c}10.66 \pm 1.15 \\
\mathrm{~mm}\end{array}$ & $\begin{array}{c}13.20 \pm 1.31 \\
\mathrm{~mm}\end{array}$ & $\begin{array}{c}29.9 \pm 1.8 \\
\mathrm{~mm}\end{array}$ & $\begin{array}{c}26.8 \pm 1.15 \\
\mathrm{~mm}\end{array}$ \\
\hline $\begin{array}{l}\text { Candida } \\
\text { tropicalis }\end{array}$ & - & $\begin{array}{c}7.83 \pm 1.04 \\
\mathrm{~mm}\end{array}$ & $\begin{array}{c}10.50 \pm 0.80 \\
\mathrm{~mm}\end{array}$ & $\begin{array}{c}18.66 \pm 1.60 \\
\mathrm{~mm}\end{array}$ & $\begin{array}{c}33.3 \pm 1.5 \\
\mathrm{~mm}\end{array}$ & $\begin{array}{c}28.8 \pm 3.7 \\
\mathrm{~mm}\end{array}$ \\
\hline $\begin{array}{l}\text { Candida } \\
\text { glabrata }\end{array}$ & $\begin{array}{c}1.33 \pm 1.52 \\
\mathrm{~mm}\end{array}$ & $\begin{array}{c}13.66 \pm 3.51 \\
\mathrm{~mm}\end{array}$ & $\begin{array}{c}15.16 \pm 2.56 \\
\mathrm{~mm}\end{array}$ & $\begin{array}{c}24.5 \pm 3.77 \\
\mathrm{~mm}\end{array}$ & $\begin{array}{c}30.8 \pm 1.0 \\
\mathrm{~mm}\end{array}$ & $\begin{array}{c}37.3 \pm 2.0 \\
\mathrm{~mm}\end{array}$ \\
\hline
\end{tabular}

* Data present as mm (Mean $\pm \mathrm{SD})$

Table 3 Determination of MIC and MFC of methanolic and ethanolic extract for Candida spp*

\begin{tabular}{ccc}
\hline Extracts & MFC & MIC \\
\hline Ethanolic & $43 / 75 \pm 0.63$ & $21 / 87 \pm 0.59$ \\
\hline Methanolic & $31.25 \pm 0.71$ & $15.62 \pm 0.64$ \\
\hline
\end{tabular}

* Data present as $\mathrm{mg} / \mathrm{ml}($ Mean $\pm \mathrm{SD})$ 
Plant-based drugs are promising agents for treatment of diseases. (33). Scrophularia as a member of Scrophulariaceae has been found to possess antibacterial, antiprotozoal, antitumor, antiinflammatory, and diuretic activities and have been used in the treatment of mental, nervous and gastrointestinal conditions $(34,35)$. S. striatais traditionally used for treatment of infectious diseases. alchoholic extracts from aerial parts of $S$. striatahave higher antimicrobial activity than that of aqueous extract (36). S. striata extract was shown to have antiseptic effects in treating infections caused by gram positive and negative bacteria, fungi and virus (37-39). One of the reason in treatment of infection due to the effects of flavonol and flavonoid compounds of the $S$. striata extract in combination with cell wall structures or extracellular proteins (40).

A few studies conducted on the essential oils of species of this genus and its family revealed a significant chemical diversity. However, some compounds such as anethole, anisaldehyde, eugenol, benzaldehyde, eugenol acetate are common in the Scrophularia. On the other hand, the presence of aromatic compounds in various genera of the Scrophulariacea eis one of the characteristics of this family $(41,42)$.Also they have been known to be rich in iridoid glycosides, mainly aucubin and catalpol. Iridoids represent a large group of cyclopentan-[c]-pyran monoterpenoids occurring as constituents of sympetalous plants including ornamental as well as wild ones $(43,44)$. In this study invitro inhibitory effect of ethanolic and methanolic extract of Scrophularia striata on Candida.spp have been studied. As it was expected, ethanolic and methanolic extract of Scrophularia striata had inhibitory effects on Candida and this effect was increasing by extract concentrations. The increasing public and economic implications caused by fungi means there is a stable fighting to produce safer food crops and to develop new antifungal agents (19). Plant extracts and essential oils are potential sources of novel antimicrobial compounds against bacteria and fungi pathogens. In traditional medicine Scrophularia striata has been used for wound disinfection. On the other hand, Scrophularia is an antipyretic and it used for treatment of kidney disorders and pulmmonary canceres (21). Plants have severe ability to synthesize phenolic products. These products are secondary metabolites and serve as plant defense mechanisms by microorganisms (12). Their activity could be due to their ability to complex with extracellular and soluble proteins (15). Thus, previous reports have demonstrated that: saponins, tannins, alkaloids, terpenes, carotenoids, and flavonoids possessed antifungal activity (18). Antimicrobial flavonoids have multiple cellular targets, Instead of one specific site of action. Alternatively, these common structural features may simply be necessary for flavonoids to gain presence to or uptake into the microbial cell. It may be that flavonoids are not killing microbial cells but singly inducing the formation of microbial aggregates and thereby reducing the number of CFUs in viable counts (41).

Our study is in agreement with several reports (41). Various investigations demonstrated antifungal effects of Scrophularias triatat extract. Based on Pirbalouti et al. Scrophularia striata water extract in different concentrations (10 to $15 \mathrm{mg}$ ) had anti-candida effects on Candida albicans (25). Bahraminejad et al. (45) showed that many Iranian plants like Scrophularia striata had antifungal role on Fusarium Oxyparum and Rhizoctonia (23). GhasemiPirbalouti et al. determined anti-candida activity of some of the Iranian medicinal plants. The extracts from different plant species studied showed antifungal activities, with the diameters of inhibition zone ranging from 7 to $46 \mathrm{~mm}$. The most active of the concentration was high concentrations $(50-55 \mu \mathrm{L})$ inhibiting the growth of yeast. Extracts of Scrophularia striata showed antifungal activity against Candida albicans. Among the plants tested essential oil the extracts of Scrophularia striata and Ziziphus spinachristi showed the best anti-Candida activity (22).

Bahmani et al. showed MIC of Scrophularia deserti ethanolic extract in dose of $480 \mathrm{mg} / \mathrm{ml}$ on Saprolegnia parasitica was $61 \%$ and for Formalin standard control was $57 \%$, which it demonstrate antimicrobial effects of Scrophularia deserti (46). Other study showed antimicrobial effects of Scrophularia striata ethanolic extract on E.coli, in both agar diffusion and microdilution methods. Its ethanolic extract showed MIC and MBC as $90 \mathrm{mg} / \mathrm{ml}$ and $100 \mathrm{mg} / \mathrm{ml}$, respectively, but water extract had no anti-microbial activity (47). Moreover, Scrophularia striatat extract had anti-viral properties (48). Anti-inflammatory and antibiotic properties of Scrophularia striatat reported 
in many studies (49). It is suggested that Scrophularia striatat extract could be used as an anti-inflammatory agent. Additionally, it could inhibit Helminth in gastro intestinal tract disorder patients (50). Many studies showed Scrophularia striata extract have inhibitory effect on various microorganisms and in some studies this extracts have better effects in comparison with antibiotics. However, research on the anti-fungal and anti-bacterial effects of Scrophularia striata are in the early stages, and most reports about this plant are based on anti-bacterial, anti-viral and anti-inflammatory traits. This explains the use of this plant in folk medicine for the treatment of various diseases whose symptoms might involve fungal infections. Future phytochemical research is needed to identify the active principles responsible for the antifungal effects of this medicinal plant.

\section{Conclusion}

In vitro antifungal activity of the methanolic and ethanolic extract of Scrophularia striata on fungi was tested. The methanolicand ethanolicextract of Scrophularia striata showed antifungal activity against Candida albicans ATCC 1167, ATCC 1677, tropicalis, and glabrata. Major investigations should be performed on a wider range of fungi in order to determine which component of the extract shows the most potent antifungal activity. The antifungal activity could also be a result of the synergism of its components.

\section{Conflict of Interest}

The authors declared no conflict of interest.

\section{References}

1. Maryin GS, Mannino DM. The epidemiology of sepsis in the united states from 1979-2000. N Engl J Med. 2003;348:154654.

2. Eggimann P, Garbino J, Pittet D. Management of candida species infection in critically ill patients. Lancet Infect Dis 2003;3:772-85.

3. Patterson TF, Revanker SG, Kirkpatrik WR, Dib O, Fothergill AW, Redding SW, et al. Simple method for detecting Fluconazol-Resistant Yeast whit chromogenic Agar. J Clin Microbiol 1996;34:1794-97.

4. Avijigan M, Saadat M, Nilforoosh-zade MA, Hafezi M. AntiFungal effect of Echinophoraplatyloba extract on some common dermatophytes J Med Plan 2006;2:10-16.

5. Troillet N, Durussel C, Bille J, Glaouser MP, Chave JP. Correlation between in vitro susceptibility of candida albicans and fluconazole-resistance oropharyngeal candidiasis in HIV- infected patients. Eur J Clin Microbiol Infect Dis 1993;12: 911-5.

6. Khosravi A, Malecan M. Effects of lavandulas toechas extracts on staphylococcus aureus and other gram negative bacteria. J Qazvin Univ Med Sci 2004;7:3-9.

7. Bannerman RH, Barton J, wen C. Traditional medicine and health care coverage, UK:MAC. Millans/spoottis wood 1993;99-100

8. Appleton SS. Candidiasis: pathogenesis, Clinical Characteristics, and Treatment. J Calif Dent Assoc 2000;28:442-8.

9. Borris RP. Natural Products research: perspectives from a major pharmaceutical company. J Ethnopharmacol 1996;51:29-28.

10. Zargari A. Medical plants. 7th ed. Tehran: Tehran university pub.1997.

11. Velg J, Stodo L. Medical plants. Tehran: Ghoghnoos 1991.

12. Lersten NR, Curtis JD. Anatomy and distribution of foliar idioblasts in Scrophularia and Verbascum (scrophulariaceae). Am J Bot 1997;84:1638.

13. Ghahreman A. Flora's color of Iran. RIFR1975-1999;1-20.

14. Mozaffarian V. A Dictionary of Iranian Plant Names. Tehran: FarhangMo'aser. 1999.

15. Chalabian F, Norouzi H, Mossavi S. A study of growth inhibitory effect of essential Oils of seven species from different families on some kinds of microbes. J Med Plan 2003;3:37-42.

16. Shamsa F, Monsef $\mathrm{H}$, Ghamooshi R, Verdian-rizi M. Spectrophotometric determination of total alkaloid in some Iranian medical plants. Thai J Pharm Sci 2008;32:17-20.

17. Tasdemir D, Burn R, Franzblau SG, Sezgin Y, Calis I. Evaluation of antiprotozoal and antimycobacterial activities of the resinglycosides and the other metabolites of Scrophularia Cryptophila. Phytomedichne 2008;15:209-15.

18. Sherafati-Chaleshtori F, Sherafati-Chaleshtori R, Momeni M Antimicrobial effect of aqueous and ethanolic extracts of Scrophularia (Scrophularia striata ) on E. coli in vitro. J SKUMS 1998;32-7.

19. Abbasi N, AziziJalilian F, Abdim M, Saifmanesh M. A Comparative Study of the antimicrobial effect of Scrophularia striata Boiss: extract and selective antibiotics against staphylococcus aureus and Pseudomonas aeroginosa. J Med Plan 2007;1:10-8.

20. Bahmani $M$, Eftekhari $Z$. An ethno veterinary study of medicinal plants in treatment of diseases and syndromes of herd dog in southern regions of Ilam province, Iran. Comp Clin Pathol 2013;22:403-40

21. Ahmed B, Al-Rehaily AJ, Al-Howirini TA, El- Asyed kA, Ahmad MS. Scrophularia D2 and Harpagoside-B: Two new iridoid glycosides and their anti diabetic and antiinflammatory activity. Biol Pharm Bull 2003;462-7.

22. Pirbalouti AG, Bahmani M, Auijgan M. Anti-Candida activity of some of Iranian medical plants cultivated in Iran. E J Bio 2009;5:85-8.

23. Bahraminejad $\mathrm{S}$, Abbasi $\mathrm{S}$, Fazeli $\mathrm{M}$. In vitro antifungal activity of 63 Iranian plant species against three different plant species against three different plant pathogenic Fungi. Afr J Biotechnol

2011:10:16193-201. 
24. Bahmani M, Zamani P, Raeisee M, Bahmani F, MohebnasabM, Alizadeh N. Effect of anti saprolegniaparasitica of wild snapdragon (Scrophulariadeserti) in comparison with formalin. Proceedings of the first national congress of economic diseases of rainbow trout. Shahrekord, Iran: Islsmic Azad University of Shahrekord 2009;68.

25. Hajiaghaee R, Monsef-Esfahani HR, Khorramizadeh MR, Saadat F, Shahverdi AR, Attar F. Inhibitory effect of aerial parts of Scrophularia striata on matrix metalloproteinases expression. Phytother Res 2007;21:1127-9.

26. Vahabi $S$, Najafi E, Alizadeh S. In vitro antimicrobial effects of some herbal essences against oral pathogens. J Med Plants Res 2011;5:4870-78.

27. Stavri M, Mathew KT, Gibbons S. Antimicrobial constituents of Scrophularia deserti. Phytochem 2006;67:1530-33.

28. Fernandez MA, Garcia MD, Saenz MT. Antibacterial activity of the phenolic acids fractions of Scrophulariafrutescens and Scrophulari asambucifolia. J Ethnopharmacol 1996;53:11-4.

29. Azadmehr A, Afshari A, Baradaran B, Hajiaghaee R, Rezazadeh S, Monsef-Esfahani H. Suppression of nitric oxide production in activated murine peritoneal macrophages in vitro and ex vivo by Scrophularia striata ethanolic extract. J Ethnopharmacol 2009;124:166-9.

30. Cosentino S, Tuberoso CIG, Pisano B, Satta M, Mascia V, Arzedi E, Palmas F. In vitro antimicrobial activity and chemical composition of Sardinian Thymus essential oils.Lett Appl Microbial 1999;29:130-135.

31. Karaman I, Sahin F, Gulluce M, Ogutcu H, Sengul M, Adiguzel A. Antimicrobial activity of aqueous and methanol extracts of Juni- perusoxycedrus L. J Ethnopharmacol 2003;85:231-5.

32. Ozaslan M, Didem Karagoz I, Kalender ME, Kilic IH, Sari I, Karagoz A. In vivo Antitumoral Effect of Plantago major L. Extract on Balb/C Mouse with Ehrlich Ascites Tumor. Am J Chin Med 2007;35:841-51.

33. Zamanian-Azodi M, Rezaie-Tavirani M, Heydari-Kashal S, Kalantari S, Dailian S, Zali H. Proteomics analysis of MKN45 cell line before and after treatment with Lavender aqueous extract. Gastroenterol Hepatol Bed Bench 2012;5:35-42.

34. Sabzevari O, Hosseini A, Paydar H, Monsef-Esfahani H-R. Hepatoprotective activity of Scrophularia striata against acetaminophen-induced liver injury in mice. Toxicol Lett 2008;6:634.

35. Mosaddegh M, Naghibi F, Moazzeni H, Pirani A, Esmaeili S. Ethnobotanical survey of herbal remedies traditionally used in Kohghiluyehva Boyer Ahmad province of Iran. J Ethnopharmacol 2012;141:80-95.

36. Azadmehr A, Afshari A, Baradaran B, Hajiaghaee R, Rezazadeh S, Monsef-Esfahani H. Suppression of nitric oxide production in activated murine peritoneal macrophages in vitro and ex vivo by Scrophularia striata ethanolic extract. J Ethnopharmacol 2009;124:166-9.
37. Bahmani M, Qorbani M, Momtaz M, Bahmani E, Rafieian $M$. The comparison of the in-vitro effects of Scrophularia deserti plant and amphotricin B on Candida albicans. Arak Uni Med Sci J. 2011;13:15-21.

38. Azadmehr A, Afshari A, Baradaran B, Hajiaghaee R, Rezazadeh S, Monsef-Esfahani H. Suppression of nitric oxide production activated murine peritoneal macrophages in vitro and exvivoby Scrophularia striata ethanolic extract. J Ethnopharmacol 2009;124:166-9.

39. Sharafati-Chaleshtori R, Rafieian-Kopaei M. Screening of antibacterial effect of the Scrophularia striata against E. coli in vitro. J Herb Med Pharmacol 2014;3:31-4.

40. Mahboubi M, Kazempour N, Nazar ARB.Total phenolic, total flavonoids, antioxidantand antimicrobial activities of Scrophularia striata Boiss extracts. Jundishapur J Nat Pharm Prod 2013;8:15-9.

41. Tim Cushnie TP, Andrew J L. Antimicrobial activity of flavonoids. Int J Antimicrob Agents 2005; 26:343-56.

42. Rastogi RP, Mehrotra BN. Compendium of Indian Medicinal Plants. CSIR 1998;435.

43. Ardeshirylajimi A, Barzegar M, Rezaei-Tavirani M, Hashemi M, Heidari S, Moghadamnia S H, et al. Effects of Scrophularia striata extract on human fibroblast cells. Med Sci J 2009;19:168-72.

44. Kambizi L, Afolayan AJ. Extracts from Aloe ferox and With aniasomnifera inhibit Candida albicans and Neisseria gonorrhoea. Afr J Biotech 2008;7:12-5.

45. Baron EJ, Finegold SM. Methods for testing antimicrobial effectiveness, Bailey \& Scott's diagnostic Microbiology. 8th ed. New York: Mosby Company 1990.

46. NCCLS document M27-A-Reference Method for broth dilution antifungal susceptibility testing of yeasts Approved 1977;17:1-29

47. Bahmani M, Ghorbami M, Momtaz H, Bahmani E, Rafieian M. The comparison of the in- vitro effects of Scrophularia striata deserti plant and amphotricin B on Candida albicans. Arak Med Uni J 2011;13:15-21.

48. Bahrami AM. Pathology of worm infestation in ovine and its treatment with two different plants extraction.Afr J Biotech 2011;10:14608-17

49. Bahrami AM, Andvaladi A. Effects of Scrophularia striata Ethanolic leaves Extract on Staphylococcus areus. Int J Pharmacol 2010;6:431-4.

50. Bahrami AM. the effectiveness of Scrophularia striata on Newcastle disease, AJBAS 2011;5:2883-88. 